\title{
Documento
}

\section{Recomendaciones para el control de conflictos de intereses}

\author{
Recommendations to avoid conflicts \\ of interest with the pharmaceutical \\ companies, approved by the \\ Chilean Association \\ of Scientific-M edical Societies
}

$\mathrm{L}$ sociedades Médicas-Científicas miembros de la Asociación de Sociedades CientíficasMédicas de Chile (ASOCIMED) se comprometen a difundir entre sus socios y a apoyar entre los especialistas las siguientes recomendaciones:

1. Aceptar la menor cantidad posible de obsequios de los proveedores médicos y no aceptar obsequios físicos que por su valor representen un compromiso para el médico (la American Medical Association recomienda un máximo de US\$ 100 por año).

2. No aceptar, de parte de los proveedores médicos, el financiamiento de un viaje, sin antes asegurarse que su objetivo central es educativo y por lo tanto beneficioso para los pacientes, y que éste no genere compromiso alguno del médico con la industria.

3. Evitar toda participación activa o pública en eventos de difusión médica, cuyo control organizador dependa de proveedores médicos o donde pueda verse lesionada la neutralidad y autonomía científica.

4. En proyectos de investigación clínica vinculados a la industria farmacéutica o a los provee- dores médicos, se recomienda participar sólo en trabajos clínicos en donde los fondos o ingresos se dirigen a instituciones académicas o sin fines de lucro, como por ejemplo: las Sociedades Científicas. El o los investigadores participantes podrán percibir ingresos personales previa autorización de las autoridades de la institución a la que pertenecen.

5. Mantener siempre una actitud neutral, transparente y ética en la relación médico-paciente y con los proveedores.

6. Evitar todo tipo de exámenes, interconsultas, derivaciones de pacientes, alteraciones de licencias médicas u otros que puedan constituir conflicto de interés.

7. Evitar la promoción pública en los medios que pueda establecer algún vínculo con los proveedores.

8. No aceptar ni recibir cualquier índole de pagos de parte de los proveedores que pueda significar connivencia comercial en la atención profesional.

9. Evitar todo tipo de vínculo comercial, directo o indirecto, con los proveedores médicos.

Recibido el 12 de marzo, 2005. Aceptado el 20 de marzo, 2005.

ASOCIMED representa, a la fecha, 30 Sociedades Científicas-Médicas Chilenas, con carácter nacional, incluyendo a la Sociedad Médica de Santiago - Sociedad Chilena de Medicina Interna.

La página web de ASOCIMED se encuentra en www.asocimed.cl 
10. Declarar antes de cada presentación pública, conferencia, clase, etc., todos los vínculos comerciales, viajes u obsequios que se hayan obtenido en los últimos 3 años con los proveedores médicos.

13. Evitar participar en cualquier situación académica o editorial donde se pudiera producir un eventual conflicto de interés.
14. No aceptar ni recibir pagos de parte de empresas farmacéuticas, laboratorios clínicos, otras empresas proveedoras de insumos médicos ni de centros de diagnóstico o tratamiento especializados donde se puede producir un conflicto de interés.

15. Favorecer siempre una conducta médica ética, transparente y distanciada de cualquier forma de conflicto de interés. 